\title{
Teknoloji Yoğun Malların Sektörel İhracatı: Türkiye
} Örneği ${ }^{1}$

\section{Enes BOLKAN ${ }^{2}$}

Fatih KAPLAN ${ }^{3}$

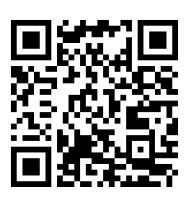

\begin{tabular}{lcc}
\hline Geliş Tarihi/ Received & Kabul Tarihi/ Accepted & Yayın Tarihi/ Published \\
$01 / 04 / 2020$ & $01 / 07 / 2020$ & $15 / 07 / 2020$ \\
\hline $\begin{array}{l}\text { Citation/Atıf: Bolkan, E. ve Kaplan, F, (2020), Teknoloji Yoğun Malların Sektörel İhracatt: } \\
\text { Türkiye Örneği, Atatürk Üniversitesi İktisadi ve İdari Bilimler Dergisi, 34(3): 1001-1020, DOI: } \\
\text { 10.16951/atauniiibd.713014 }\end{array}$ \\
\hline
\end{tabular}

Öz: Bu çalışmanın amacı, Türkiye'nin teknoloji yoğun mal ihracatına dış gelir ve döviz kurunun etkisini incelemektir. $\mathrm{Bu}$ amaç doğrultusunda teknoloji yoğunluğuna göre 26 sektörün mal ihracat1, reel döviz kuru ve AB'nin Gayri Safi Yurtiçi Hasıla (GSYIH) değişkenleri için 2003:I-2017:IV dönemlerini kapsayan üçer aylık veriler kullanılmıştır. Çalışmada zaman serisinin önsel testlerinden yapısal kırılmalı birim kök testleri ile yapısal kırılmalı eşbütünleşme testi yapılmıştır. Teknoloji yoğunluğuna göre sınıflandırılan 26 sektörün ihracatına reel döviz kuru ve dış gelirin etkisi Tam Değiştirilmiş En Küçük Kareler Yöntemi (FMOLS) ile tahmin edilmiştir. Yapılan ekonometrik analizlerden elde edilen sonuçlara göre yüksek ve orta-yüksek teknoloji ürünleri sektörleri ihracatının reel döviz kuru ve dış talep esnekliğinin diğer sektörlerden daha yüksek olduğu tespit edilmiştir.

Anahtar Kelimeler: Reel Döviz Kuru, Teknoloji Yoğun Mallar, Milli Gelir

The Sectoral Export of Technology Intensive Goods: Case of Turkey

Abstract: The aim of this study was to examine the impact of Turkey's technology intensive goods exports on foreign income and foreign exchange. For this purpose, the exports of 26 sectors according to technology intensity, quarterly data covering the 2003: I - 2017: IV periods for real exchange rate and the EU's Gross Domestic Product (GDP) variables were used. In the study, structural fracture unit root tests and structural fracture cointegration test were performed, which are a preliminary tests of the time series. The effect of real exchange rate and foreign income on the exports of 26 sectors classified by technology intensity was estimated by the Fully Modified Least Squares Method (FMOLS). According to the results obtained from the econometric analysis, it was determined that the real exchange rate and foreign demand elasticity of the exports of high and medium-high technology products sectors were higher than the other sectors.

Keywords: Real Exchange Rate, Technology Intensive Goods, National Income

\footnotetext{
${ }^{1}$ Bu çalışma, Doç. Dr. Fatih Kaplan danışmanlığında Tarsus Üniversitesi Lisansüstü Eğitim Enstitüsünde yürütülen "Teknoloji Yoğun Malların Sektörel İhracatı: Türkiye Örneği ” başlıkl yüksek lisans çalışmasından türetilmiştir.

${ }^{2}$ https://orcid.org/0000-0002-5718-8265

${ }^{3}$ Doç. Dr. Tarsus Üniversitesi, Uygulamalı Bilimler Fakültesi, Uluslararası Ticaret ve Lojistik Bölümü, https://orcid.org/0000-0001-7417-1126
} 
Teknoloji Yoğun Malların Sektörel İhracatt: Türkiye Örneği

\section{EXTENDED SUMMARY}

\section{Purpose}

The aim of this study was to examine the impact of Turkey's technology intensive goods exports on foreign income and foreign exchange.

\section{Research Question}

Do foreign income and foreign exchange rate have an effect on the Turkey's technology intensive goods exports?

\section{Literature Review}

In the literature review; Turkey was found to be a limited number of academic studies on the subject area. One of these studies Ekizceleroğlu (2011), knowledge-intensive goods, the impact of foreign trade capital investments in Turkey, exchange rate and Gross Domestic Product (GDP) analyzed with variables. The another study, Şahbaz, Yanar and Adıgüzel (2014), documented that the Research and Development (R\&D) expenditures are in the share of GDP and the export of high-tech goods.

\section{Methodology}

The structural fracture unit root tests and structural fracture cointegration test were performed, which are a preliminary tests of the time series. The effect of real exchange rate and foreign income on the exports of 26 sectors classified by technology intensity was estimated by the Fully Modified Least Squares Method (FMOLS).

\section{Conclusion}

According to the results obtained from the econometric analysis, it was determined that the real exchange rate and foreign demand elasticity of the exports of high and medium-high technology products sectors were higher than the other sectors.

\section{Giris}

Bilgi teknolojilerinin gelişmesi ve küreselleşmenin boyut değiştirmesi ile birlikte teknoloji yoğun mallar dünya ticaretinde daha fazla yer almaya başlamıştır. Bunların neticesinde dünya ekonomisine daha fazla entegre haline gelen ülkelerin, dış ticaret politikalarında teknoloji yoğun malların ihracatına daha fazla önem verdikleri gözlemlenmiştir. Ekonomik Kalkınma ve İşbirliği Örgütü (OECD: The Organisation for Economic Co-operation and Development) ülkelerinde ihracatın sektörel bileşiminde son yıllarda ortaya çıkan gelişmeler incelendiğinde uluslararası ticaretin önemli artış gösterdiği, teknoloji yoğun malların ihracat performansının diğer sanayi gruplarından önemli ölçüde yüksek olduğu ortaya çıkmıştır (Saygıl1, 2003: 53). OECD tarafindan hazırlanan 2011 yılı Kalkınma İşbirliği Raporu'nda da benzer sonuçlar gözlemlenmiştir. 2011 yılı OECD verilerine göre, ihracat ile ilgili artışların ve bu konudaki gelişmelerin büyük ölçüde yüksek teknoloji kullanan sektörlerle ilişkili olduğu, teknoloji yoğunluğu düşük sektörlerin ihracat performanslarının oldukça düşük olduğu gözlemlenmiştir (OECD, 2011). 
Sektörlerin teknoloji yoğunluklarına göre sınıflandırılmasında doğal kaynaklara dayalı, düşük, orta ve yüksek teknoloji olmak üzere dört dereceli bir sınıflandırma bulunmakta ve sınıflandırmanın firmalar bazında değil sektörler bazında yapıldığı görülmektedir (Sekmen, 2013: 9). OECD'nin yayınlarında ise teknoloji düzeyleri, düşük, orta-düşük, orta-yüksek ve yüksek olmak üzere dört şekilde sınıflandırılmaktadır (OECD, 2007:4). Yüksek teknoloji ve orta-yüksek teknoloji sektörleri, bilgi yoğun sanayi sektörleri olarak değerlendirilmektedir (Saygıll, 2003: 8). Sanayi sektörü dışında iletişim, bankacılık, sigortacılık, müşavirlik, eğitim ve sağlık hizmetleri de bilgi yoğun hizmet sektörleridir. OECD tarafından yapılan imalat sanayi sektörlerinin teknoloji yoğunluğu sinıflandırılmasına göre, yüksek teknoloji sektörleri grubunda havacılık ve uzay, bilgisayar ve büro makinaları, elektronik-haberleşme ve ilaç sektörleri; orta-yüksek teknoloji grubunda ise mesleki bilim ve ölçüm cihazları, taşıt araçları, elektrikli ve elektriksiz makinalar ve ilaç hariç kimyasallar gibi sektörler bulunmaktadır (Calvino, Criscuolo, Marcolin, ve Squicciarini, 2018: 4)

Dünya Bankası'nın 2018 yılı verilerine göre Türkiye teknoloji yoğun mallar ihracatında 82 ülke arasından 49'uncu sırada yer almaktadır. Türkiye'nin sürdürülebilir ihracat performansı sergilemesi ve dünya sıralamasında ön sıralarda yer alabilmesi için teknoloji yoğun malların ihracatının sektörel bazda araştırılması önem arz etmektedir. Bu nedenle çalışmanın amacı, Türkiye'nin teknoloji yoğun mal ihracatının dış ticarete etkisini ortaya çıkarmaktır. Yapılan literatür taramasında Türkiye'yi konu alan kısıtlı sayıda akademik çalışmalar olduğu görülmüştür. Söz konusu bu çalışmalardan Ekizceleroğlu (2011), Türkiye'deki bilgi yoğun malların dış ticarete etkisini sermaye yatırımları, döviz kuru ve Gayri Safi Yurtiçi Hasıla (GSYIH) değişkenleri ile analiz etmiştir. Şahbaz, Yanar ve Adıgüzel (2014) çalışmalarında, araştırma ve geliştirme (Ar-Ge) harcamalarının GSYİH içindeki payı ile ileri teknoloji mallarının ihracatı üzerindeki etkilerini incelemiştir. Türkiye üzerine yapılan akademik çalışmalar arasında ihracatı sektörel bazda inceleyen çalışmaların kısıtlı sayıda olması nedeniyle çalışmanın literatürdeki bu boşluğu doldurması beklenmektedir.

Çalışma dört bölümden oluşmaktadır. Çalışmanın birinci bölümünde genel bir giriş yapılmıştır. İkinci bölümünde teknoloji yoğun malların dış ticareti ile ilgili literatür taramasına yer verilmiştir. Üçüncü bölümde ise, çalışmanın amacına uygun olarak analizde kullanılan veri seti tanıtılmış, ardından modellere ve yöntemlere yer verilerek, analiz sonuçları tablolar halinde sunulmuştur. Son bölümde ise çalışmadan elde edilen sonuçlar özetlenmiştir.

\section{Literatür Taraması}

Yapılan literatür taraması; sadece Türkiye üzerine yapılan çalışmalar, Türkiye'nin dahil olduğu ülke örneklemi (yatay kesit- panel veri veya çok ülkeli 


\section{Teknoloji Yoğun Malların Sektörel İhracatı: Türkiye Örneğgi}

zaman serisi) çalışmaları ve Türkiye'nin dahil olmadığı diğer çalışmalar olmak üzere üç grupta incelenmiştir. Söz konusu gruplandırma yapılırken teknoloji yoğun mallar ile bilgi yoğun mallar kavramın iç içe olduğu görülmüş, bu nedenle her iki kavramı da kullanan çalışmalar arasında ayrım yapılmamıştır.

Sadece Türkiye'nin ele alındığı birinci grup çalışmalardan Ekizceleroğlu (2008, 2011), çalışmalarında Türkiye'nin bilgi yoğun mal ihracatının bilgi yoğun mal ithalatıyla doğrudan bağlantılı olduğunu tespit etmiştir. Özdamar (2014) çalışmasında Türkiye'nin AB'ye ihraç ettiği imalat ürünlerinin ağırlıklı olarak orta-ileri teknoloji düzeyinde olduğunu, Türkiye'nin yüksek teknoloji anlamında rekabet gücünün oldukça düşük olduğunu, düşük teknolojik imalat ürünlerinde AB'ye kıyasla tam bir rekabet avantajı, orta-ileri teknoloji açısından ise sınırlı bir rekabet avantajı söz konusu olduğunu gözlemlemiştir. Telatar, Değer ve Doğanay (2016) ise düşük ve orta teknolojili mal ihracatı Türkiye'nin ekonomik büyümesi üzerinde pozitif ve istatistiki açıdan anlamlı etkilere sahip olduğunu ileri sürmüştür. Öte yandan Telatar vd. (2016) hem orta hem de ileri teknoloji yoğunluklu mal ihracatından ekonomik büyümeye doğru tek yönlü nedensellik de gözlemlemiştir.

Çalışılan ülke örneklemine Türkiye'nin de dahil edildiği çalışmalarından Seyoum (2004), 54 ülke için yatay kesit analizi yaptığı çalışmasında döviz kuru hariç diğer tüm değişkenlerin ileri teknolojili ürün ihracatı üzerinde güçlü pozitif bir etkisi olduğunu tespit etmiştir. Bir başka çalışmada ise Özer ve Çiftçi (2009) OECD ülkelerinde Ar-Ge harcamalarının genel ihracatı, bilgi ve iletişim teknolojileri ihracatı ve ileri teknoloji ihracatı olmak üzere 3 farklı modeli panel veri analizleri ile incelemiştir. Özer ve Çiftçi (2009), gelişmekte olan ülkelerde sürdürülebilir bir büyüme oranının yakalanması için katma değeri yüksek ürünler olan ileri teknoloji ürünlerinin üretilmesi ve bunların ihraç edilmesinin önemli olduğunu vurgulamıştır. OECD ülkelerinin ele alındığı bir başka çalışmada ise, Işık ve Kılınç (2013) bilgi ekonomisi ile ekonomik büyüme arasında beklentilere uygun olarak pozitif yönlü bir ilişki olduğunu tespit etmiştir.

Göçer (2013) 10 Asya ülkesi ve Türkiye için yaptığı çalışmada Ar-Ge harcamalarındaki artışın bilgi ve iletişim teknolojileri ihracatı ve yüksek teknoloji ihracatını doğrudan, diş ticaret dengesini ise dolaylı yoldan etkilediğine ulaşmıştır. Şahbaz, Yanar ve Adıgüzel (2014) 17 AB üyesi ülke ve Türkiye'nin ileri teknoloji ihracatı ile Ar-Ge harcamaları arasında pozitif yönlü ve anlamlı bir ilişki olduğunu bulmuştur. Topallı (2015) ise Türkiye, Tayland, Güney Kore, Singapur, Hindistan ve Brezilya'yı ele aldığ çalışmasında doğrudan yabancı sermaye yatırımları, ekonomik büyüme ve teknoloji ihracatı arasındaki nedensellik ilişkisini bu ülkeler için araştırmışıtır. Türkiye açısından sonuçlara bakıldığında doğrudan yabancı sermaye yatırımlarından yüksek teknoloji ihracatına doğru tek yönlü nedensellik ilişkisi vardır. Şahin ve Aşan (2015) çalışmalarında, kriz sürecinde OECD ülkelerinin Bilgi ve İletişim Teknolojileri (BİT) ihracatından aldıkları pay dönüşümü shift-share tekniği ile 
analiz edilmiştir. Yapılan analiz sonucunda, Türkiye'nin analiz döneminde BİT ihracatında pay kaybı yaşayan ülkeler arasında olduğu gözlemlemiştir. Çetin (2016) çalışmasında Malezya, Çin, Güney Afrika, Tayland, Meksika, Brezilya ve Türkiye' de Ar-Ge harcamalarının teknoloji yoğun mal ihracatına pozitif ve anlamlı etki ettiği tespit edilmiştir.

Yücel (2016) yükselen ekonomilerde (Türkiye dahil) uzun dönemde ArGe harcamalarının, patent sayılarının ve bilimsel yayın sayılarının ihracat üzerinde pozitif ve anlamlı bir etkiye sahip olduğu gözlemlenmiştir. Özkan ve Yılmaz (2017) AB'ye üye 12 ülke ve Türkiye'nin Ar-Ge harcamalarının teknoloji yoğun mal ihracatını ve gayri safi yurtiçi hasılayı pozitif yönde etkilediği tespit edilmiştir. Kızılkaya, Sofuoğlu ve Ay (2017) çalışmasında verilerini kullandığı 12 ülkede (Türkiye dahil) doğrudan yabancı sermaye yatırımları ve dışa açıklığın teknoloji yoğun mal ihracatını pozitif yönde etkilediğini tespit etmiştir. Yıldız (2017) Brezilya, Rusya, Hindistan, Çin, Güney Afrika (BRICS) ülkelerinde ve Türkiye'de teknoloji yoğun mal ihracatındaki artışların ekonomik büyümeyi arttırıcı etkisinin olduğu sonucuna ulaşılmıştır.

Diğer ülke ve ülke gruplarına yapılan çalışmalardan Gani (2009) Birleşmiş Milletler Kalkınma Programı (UNDP) tarafından geliştirilen ve Teknoloji Başarı Endeksi'nde yer alan ülkeleri lider ülkeler, potansiyel ülkeler ve dinamik benimseyen ülkeler olarak üç ana başlık altında gruplandırılmış; lider kategorisinde olan ülkelerde yüksek teknolojili ürün ihracatının fert başına ekonomik büyüme üzerinde olumlu bir etkisi olduğu görülmüştür. Potansiyel lider kategorisindeki ülkelerde yüksek teknoloji ihracat katsayısı pozitif çıkarken buna karşın istatistiksel olarak anlamsız olduğu tespit edilmiştir. Sandu ve Ciocanel (2014), 26 AB ülkesi üzerine yaptı̆g çalışmasında, kamu sektörü Ar-Ge harcamalarında yapılan \%1'lik bir artış 2 yıl sonraki yüksek teknoloji ihracatını \%8 oranında artırırken, özel sektör Ar-Ge harcamalarında yapılan $\% 1$ 'lik bir artış aynı yılın yüksek teknoloji ihracatını \%9 oranında artırdığı bulunmuştur. K1lıç, Bayar ve Özekicioğlu (2014) G-8 ülkelerinde Ar-Ge harcamaları ve reel efektif döviz kurunun, yüksek teknolojili ürün ihracatı üzerinde pozitif etkiye sahip olduğu belirlenmiştir. Ayrıca Ar-Ge harcamaları ile yüksek teknolojili ürün ihracatı ve Ar-Ge harcamaları ile reel efektif döviz kuru arasında çift yönlü nedensellik, yüksek teknolojili ürün ihracatından reel efektif döviz kuruna doğru tek yönlü bir nedensellik olduğu da tespit edilmiştir. Fotros ve Ahmadvand (2017) İran'ın ekonomik büyümesinde teknoloji yoğun mal sektörlerinin ithalat ve ihracatının olumlu yönde etkisinin bulunduğunu gözlemlenmiştir.

\section{Model, Veri Seti, Yöntem ve Analiz Sonuçları}

Çalışmanın amacına uygun olarak, temel Model 1 aşağıdaki gibi oluşturulmuştur. Model 1'in oluşturulmasında Orman (2015), Erarslan (2017), 
Gürtay (2017), Kayalı (2017), Albayrak (2018) ve Tekçeken (2018) çalışmaları referans alınmıştır.

$I H R_{t}=\alpha_{0}+\alpha_{1} G S Y \dot{I} H_{t}+\alpha_{2} R D K_{t}+\alpha_{3}$ Kriz $_{t}+e_{t}$

Model 1 'de $I H R_{t}$; teknoloji yoğunluğuna göre sinıflandırılan sektörlerin her biri için Türkiye'nin ürün ihracatını, GSYİH; AB'nin gayri safi yurtiçi hasılasını, RDK; Türkiye açısından reel döviz kur endeksini ve Kriz 2008-2010 küresel ekonomik krizini temsil eden kukla değişkenini, $e_{t}$ beyaz gürültü (white noise) sürecine sahip hata terimini ifade etmektedir. Çalışmada 2003:q12017:q4 dönemlerini kapsayan üçer aylık verilerden yararlanılmıştır. Söz konusu değişkenlere ait serilerden; GSYİH serisi Avrupa İstatistik Ofisi (European Statistics Office-Eurostat) veri tabanından, Türkiye'ye ait reel döviz kuru endeksi serisi TCMB veri tabanından ve Türkiye'nin teknoloji yoğun mal ihracat serileri sektörel bazda TÜIK'in veri tabanından alınmıştır. Analizde kullanılan değişkenlerin kısaltmaları, tanımlamaları ve temin edildikleri veri tabanlarına ilişkin bilgiler Ek 1' de yer verilmiştir.

İhracat serileri, yüksek teknoloji yoğun, orta yüksek teknoloji yoğun, orta düşük teknoloji yoğun ve düşük teknoloji yoğun sektörler olmak üzere dört ana sinıfa ayrılmaktadır. Söz konusu sektörlere ait kodlara ve bu kodlara ait açılamalara Ek. 2' de yer verilmiştir.

\subsection{Birim Kök Testleri ve Sonuçları}

Ekonometrik analizler, serilerin durağanlık derecesine önemli ölçüde duyarlıdır. Serilerin durağanlık dereceleri göz önünde bulundurulmadan yapılan analizlerde hatalı / sapmalı sonuçlara ulaşılması olasılığı oldukça yüksektir (Dikmen, 2012: 304). Bu nedenle çalışmada kullanılan serilerin birim kök analizlerinin yapılması gerekmektedir. Geleneksel birim kök testleri Dickey ve Fuller'ın 1979 (DF) ve 1981 (ADF) yılındaki çalışmaları ile başlamış olup, bu testte serinin bir dönem önceki değerinden ne ölçüde etkilendiği belirlenmeye çalışılmaktadır. Trend içeren serilerin durağanlığının test edilmesinde ADF testinin zayıf kalması nedeniyle Phillips ve Perron (1988) tarafından geliştirilen Birim Kök Testi'nin, ADF Birim Kök Testi'nden daha güçlü olduğu kabul edilmektedir. P-P Birim Kök Testi'nde, birim kökün varlığı hareketli ortalama (Moving Average: MA) süreci kullanılarak araştırılmaktadır.

Analiz döneminde ekonomiyi etkileyen kriz, savaş, doğal afet veya politika değişimi gibi önemli olaylar olduğunda, bu olaylar seri üzerinde yapısal bir değişime (kırılmaya) neden olabilmektedir. Seride yapısal kırılma varken bunu göz önünde bulundurmaksızın yapılacak analizler, sapmalı sonuçlar verecektir (Glynn, Perera ve Verma, 2007: 3). Bu nedenle yapisal kırılmalı birim kök testleri geliştirilmiştir. Yapısal kırılmalı ilk birim kök testlerinden biri Zivot ve Andrews'a (1992, ZA) ait olan tek kırılmalı birim kök testidir. Lee ve Strazicich (2003, LS), uzun zaman serilerinde tek yapısal kırılmalı testlerin yeterli olmayacağını ifade ederek, iki yapısal kırılmanın varlığını göz önünde 
bulunduran bir test geliştirmiştir. Lee ve Strazicich (2003: 1083) aşağıdaki modelleri kullanmıştır:

Model AA: Sabit Terimde Çift Kırılmalı Model

$$
\begin{gathered}
Y_{t}=\mu_{1}+\left(\mu_{2}-\mu_{1}\right) D_{1 t}+\left(\mu_{3}-\mu_{1}\right) D_{2 t}+\gamma_{1} t+\beta Y_{t-1} \\
+\sum_{i=1} \varphi_{i} \Delta Y_{t-i}+e_{t}
\end{gathered}
$$

Model BB: Trendde Çift Kırılmalı Model

$$
\begin{gathered}
Y_{t}=\mu_{1}+\left(\gamma_{2}-\gamma_{1}\right) D_{3 t}+\left(\gamma_{3}-\gamma_{1}\right) D_{4 t}+\gamma_{1} t+\beta Y_{t-1} \\
+\sum_{i=1} \varphi_{i} \Delta Y_{t-i}+e_{t}
\end{gathered}
$$

Model CC: Sabit Terimde ve Trendde Cift Kirılmalı Model

$$
\begin{aligned}
Y_{t}=\mu_{1}+\left(\mu_{2}-\right. & \left.\mu_{1}\right) D_{1 t}+\left(\mu_{3}-\mu_{1}\right) D_{2 t}+\left(\gamma_{2}-\gamma_{1}\right) D_{3 t} \\
& +\left(\gamma_{3}-\gamma_{1}\right) D_{4 t}+\gamma_{1} t+\beta Y_{t-1}+\sum_{i=1}^{p} \varphi_{i} \Delta Y_{t-i}+e_{t}
\end{aligned}
$$

$D_{1 t}, D_{2 t}, D_{3 t}$ ve $D_{4 t}$ kukla değişkenler, $T_{B 1}$ ve $T_{B 2}$ 'ler de kırılma tarihleri olmak üzere

$$
\begin{aligned}
& D_{1 t}=\left\{\begin{array}{cc}
1, & t=T_{B 1}+1 \text { iken } \\
0 & \text { Diğer Durumlarda }
\end{array} D_{3 t}=\left\{\begin{array}{cc}
t, & t>T_{B 1} \text { iken } \\
0 & \text { Diğer Durumlarda }
\end{array}\right.\right. \\
& D_{2 t}=\left\{\begin{array}{cc}
1, & t=T_{B 2}+1 \text { iken } \\
0 & \text { Diğer Durumlarda }
\end{array} D_{4 t}=\left\{\begin{array}{cc}
t, & t>T_{B 2} \text { iken } \\
0 & \text { Diğer Durumlarda }
\end{array}\right.\right.
\end{aligned}
$$

seklinde tanımlanmaktadır. LS birim kök testinin hipotezleri:

$H_{0}: \mu_{1}=\mu_{2}=\mu_{3} v e \beta=1$ Sabitte Yapısal Kırılma Yokken, Birim Kök Var, Seri Durağan Değil

$H_{1}: \mu_{1} \neq \mu_{2} \neq \mu_{3} v e \beta<1 \quad$ Sabitte Yapısal Kırılma Varken, Birim Kök Yok, Seri Durağan

Hipotezleri test etmek için gerekli olan kritik değerler, Lee ve Strazicich (2003) çalışmasında yer almaktadır (Lee ve Strazicich, 2003: 1082-1089).

Lee ve Strazicich (2004) ve (2013) çalışmalarında LM tipinde tek kırılmaya izin veren bir başka test daha geliştirmiştir. Bu testte Lee ve Strazicich (2003)'deki çalışmasına benzer şekilde veri üretmektedir (Lee ve Strazicich, 2013:2485). Test istatistiğinin kritik değerden büyük olması halinde yapısal kırılmalı birim kök temel hipotezi reddedilmektedir. Yapılan birim kök test sonuçları Tablo 1' de yer verilmiştir. 
Teknoloji Yoğun Malların Sektörel İhracatt: Türkiye Örneği

Tablo 1. Birim Kök Testleri Sonuçları

\begin{tabular}{|c|c|c|c|c|}
\hline \multicolumn{5}{|c|}{ Tek Kırılmalı } \\
\hline & $\begin{array}{c}\text { LM } \\
\text { (LS,2004,2013) } \\
\text { Sabitte } \\
\text { Terimde }\end{array}$ & $\begin{array}{c}\text { Kirilma } \\
\text { Tarihi }\end{array}$ & $\begin{array}{c}\text { LM } \\
\text { (LS,2004,2013) } / \lambda \\
\text { Sabit Terimde ve } \\
\text { Trende }\end{array}$ & Kırılma Tarihi \\
\hline GDP & -3.394 & $2009 \mathrm{q} 1$ & $-3.672 / 0.383$ & $0.383-2008 \mathrm{q} 3$ \\
\hline RDK & -1.625 & $2013 q 2$ & $-5.668 * / 0.450$ & $0.450 /(2009 q 3)$ \\
\hline İHR15 & -1.707 & $2007 \mathrm{q} 2$ & $-3.717 / 0.317$ & $0.317 /(2007 q 3)$ \\
\hline İHR16 & -3.694 & $2012 q 2$ & $-4.129 / 0.767$ & $0.767 /(2014 q 2)$ \\
\hline İHR17 & -2.356 & $2013 q 4$ & $-3.886 / 0.367$ & $0.367 /(2008 \mathrm{q} 2)$ \\
\hline İHR18 & -3.268 & 2010q1 & $-3.622 / 0.667$ & $0.667 /(2012 q 4)$ \\
\hline İHR19 & -3.304 & $2016 \mathrm{q} 2$ & $-3.692 / 0.433$ & $0.433 /(2009 q 2)$ \\
\hline İHR20 & -1.988 & $2012 q 4$ & $-4.070 / 0.533$ & $0.533 /(2010 q 4)$ \\
\hline İHR21 & -2.042 & $2008 \mathrm{q} 2$ & $-3.860 / 0.783$ & $0.783 /(2014 q 3)$ \\
\hline İHR22 & -0.573 & $2009 q 4$ & $-4.749 * * * / 0.367$ & $0.367 /(2008 \mathrm{q} 2)$ \\
\hline İHR23 & -2.434 & $2014 q 4$ & $-3.879 / 0.283$ & $0.283 /(2007 q 1)$ \\
\hline İHR24 & -2.707 & $2014 q 4$ & $-4.199 / 0.750$ & $0.750 /(2014 q 1)$ \\
\hline İHR25 & -2.032 & $2009 q 3$ & $-3.825 / 0.550$ & $0.550 /(2011 \mathrm{q} 1)$ \\
\hline İHR26 & -1.667 & $2009 q 3$ & $-3.842 / 0.467$ & $0.467 /(2009 q 4)$ \\
\hline İHR27 & -3.624 & $2014 q 1$ & $-4.782 * * / 0.317$ & $0.317 /(2007 \mathrm{q} 3)$ \\
\hline İHR28 & -1.734 & $2008 \mathrm{q} 3$ & $-3.019 / 0.383$ & $0.383 /(2008 \mathrm{q} 3)$ \\
\hline İHR29 & -1.607 & $2008 \mathrm{q} 3$ & $-3.349 / 0.350$ & $0.350 /(2008 \mathrm{q} 1)$ \\
\hline İHR30 & -1.357 & $2007 q 4$ & $-5.550 * / 0.383$ & $0.383 /(2008 \mathrm{q} 3)$ \\
\hline İHR31 & -2.081 & $2009 q 3$ & $-3.852 / 0.533$ & $0.533 /(2010 q 4)$ \\
\hline İHR32 & -7.719 & $2012 q 2$ & $-4.627 * * / 0.633$ & $0.633 /(2012 q 2)$ \\
\hline İHR33 & -1.777 & $2010 q 4$ & $-3.987 / 0.383$ & $0.383 /(2008 \mathrm{q} 3)$ \\
\hline İHR34 & -1.501 & $2010 q 4$ & $-5.451 * / 0.367$ & $0.367 /(2008 \mathrm{q} 2)$ \\
\hline İHR36 & -2.736 & $2008 \mathrm{q} 2$ & $-3.364 / 0.367$ & $0.367 /(2008 \mathrm{q} 2)$ \\
\hline İHR351 & -3.991 & $2011 \mathrm{q} 3$ & $-6.292 * / 0.383$ & $0.383 /(2008 \mathrm{q} 3)$ \\
\hline İHR352 & -2.651 & $2008 \mathrm{q} 4$ & $-5.965 * / 0.600$ & $0.600 /(2011 q 4)$ \\
\hline IHHR353 & -3.646 & $2013 q 1$ & $-6.108 * / 0.400$ & $0.400 /(2008 \mathrm{q} 4)$ \\
\hline İHR359 & -2.946 & $2014 q 2$ & $-3.858 / 0.867$ & $0.867 /(2015 \mathrm{q} 4)$ \\
\hline İHR2423 & -3.447 & $2013 q 2$ & $-4.929 * * / 0.783$ & $0.783 /(2014 q 3)$ \\
\hline
\end{tabular}


Tablo 1 Devamı: Birim Kök Testleri Sonuçları

\begin{tabular}{|c|c|c|c|c|}
\hline \multicolumn{5}{|c|}{ Çift Kırılmalı } \\
\hline & $\begin{array}{c}\text { LM (LS,2003) } \\
\text { Sabitte } \\
\text { Terimde }\end{array}$ & $\begin{array}{c}\text { Kirılma Tarihleri } \\
\text { Sabit Terimde ve } \\
\text { Trende }\end{array}$ & LM $(\mathbf{L S}, 2003) / \lambda$ & $\begin{array}{c}\text { Kurılma } \\
\text { Tarihleri }\end{array}$ \\
\hline GDP & -3.634 & $2009 q 1-2015 q 1$ & $-8.874 * 0.367 / 0.650$ & $2009 q 1-2015 q 1$ \\
\hline RDK & -3.357 & 2007q1-2015q1 & $-6.383 * * 0.400 / 0.450$ & $2007 q 1-2015 q 1$ \\
\hline İHR15 & -2.397 & $2010 \mathrm{q} 4-2011 \mathrm{q} 4$ & $-5.886 * * * 0.433 / 0.783$ & $2010 q 4-2011 q 4$ \\
\hline İHR16 & -4.344 & $2008 \mathrm{q} 1-2012 \mathrm{q} 2$ & $-5.538 * * * 0.483 / 0.783$ & $2008 q 1-2012 q 2$ \\
\hline İHR17 & -2.766 & $2006 q 4-2012 q 4$ & $-5.873 * * * 0.367 / 0.733$ & $2006 q 4-2012 q 4$ \\
\hline İHR18 & -3.649 & $2008 q 1-2014 q 3$ & $-6.019 * * 0.367 / 0.683$ & $2008 q 1-2014 q 3$ \\
\hline İHR19 & -3.810 & $2009 q 2-2010 q 3$ & $-5.758 * * * 0.367 / 0.650$ & $2009 q 2-2010 q 3$ \\
\hline İHR20 & -2.732 & $2008 q 4-2013 q 1$ & $-5.591 * * * 0.367 / 0.767$ & $2008 q 4-2013 q 1$ \\
\hline İHR21 & -2.994 & $2006 q 3-2014 q 4$ & $-5.377 * * * 0.367 / 0.667$ & $2006 q 3-2014 q 4$ \\
\hline İHR22 & -1.745 & $2009 q 4-2011 q 3$ & $-6.715 * * 0.367 / 0.767$ & $2009 q 4-2011 q 3$ \\
\hline İHR23 & -2.644 & $2012 q 4-2014 q 4$ & $-6.092 * * 0.367 / 0.667$ & $2012 q 4-2014 q 4$ \\
\hline İHR24 & -3.308 & 2008q3-2010q1 & $-5.969 * * * 0.367 / 0.667$ & $2008 q 3-2010 q 1$ \\
\hline İHR25 & -2.355 & $2008 q 4-2011 q 3$ & $-5.898 * * * 0.3670 .650$ & $2008 q 4-2011 q 3$ \\
\hline İHR26 & -2.347 & $2008 q 3-2011 q 2$ & $-6.703 * * 0.350 / 0.650$ & $2008 \mathrm{q} 3-2011 \mathrm{q} 2$ \\
\hline İHR27 & -4.077 & 2012q3-2014q1 & $-5.927 * * * 0.417 / 0.683$ & $2012 q 3-2014 q 1$ \\
\hline İHR28 & -2.311 & $2008 q 3-2008 q 4$ & $-5.961 * * * 0.367 / 0.667$ & $2008 q 3-2008 q 4$ \\
\hline İHR29 & -2.349 & $2008 q 3-2011 q 2$ & $-6.153 * * 0.350 / 0.667$ & $2008 q 3-2011 q 2$ \\
\hline İHR30 & -1.626 & $2007 q 4-2014 q 1$ & $-7.983 * 0.383 / 0.750$ & $2007 q 4-2014 q 1$ \\
\hline İHR31 & -2.293 & $2009 q 3-2010 q 4$ & $-5.332 * * * 0.5170 .767$ & $2009 q 3-2010 q 4$ \\
\hline İHR32 & -3.683 & $2006 q 3-2011 q 4$ & $-5.632 * * * 0.383 / 0.633$ & $2006 q 3-2011 q 4$ \\
\hline İHR33 & -2.968 & 2006q3-2010q4 & $-6.790 * * 0.367 / 0.667$ & $2006 q 3-2010 q 4$ \\
\hline İHR34 & -2.968 & $2006 q 3-2010 q 4$ & $-7.079 * 0.367 / 0.667$ & $2006 q 3-2010 q 4$ \\
\hline İHR36 & -3.415 & $2008 \mathrm{q} 4-2014 q 4$ & $-7.065 * 0.400 / 0.833$ & $2008 q 4-2014 q 4$ \\
\hline İHR351 & -4.861 & $2009 q 4-2011 q 3$ & $-7.041 * 0.383 / 0.667$ & $2009 q 4-2011 q 3$ \\
\hline İHR352 & -2.886 & $2008 q 4-2012 q 2$ & $-6.095 * * 0.6000 .850$ & $2008 q 4-2012 q 2$ \\
\hline İHR353 & -6.226 & $2008 q 4-2012 q 1$ & $-7.002 * 0.250 / 0.467$ & $2008 q 4-2012 q 1$ \\
\hline İHR359 & -3.311 & $2014 q 2-2015 q 4$ & $-5.980 * * * 0.483 / 0.767$ & $2014 q 2-2015 q 4$ \\
\hline İHR2423 & -4.176 & $2007 q 42012 q 4$ & $-7.820 * 0.750 / 0.883$ & $2007 q 4-2012 q 4$ \\
\hline
\end{tabular}

*Test istatistiğine ilişkin kritik değerler Lee-Strazicich (2003), (2004) ve (2013) çalışmalarından elde edilmiştir. * \%1; ** \%5 ve *** \%10 anlamlılık düzeylerini göstermektedir. $(\lambda)$ : Franction ifade etmektedir.

Yapılan yapısal kırılmalı birim kök testleri sonuçlarına göre sabitli ve trendli modelde çift kırılmalı analizlerde serilerin durağan oldukları tespit edilmiştir. Söz konusu sonuçlar dikkate alınarak yapısal kırılma altında serilerin 
uzun dönemli hareketlerini dikkate alan eşbütünleşme analizlerinin yapılmasına karar verilmiştir.

\subsection{Eşbütünleşme Testi ve Sonuçları}

Düzey değerlerinde durağan olmayan serilerin, düzey değerleriyle yapılacak analizlerde sahte regresyon problemi olabileceği Granger ve Newbold (1974)'un çalışmasıyla gündeme gelmiştir. Daha sonra Engle ve Granger (1987: 254), düzeyde durağan olmayan, fakat aynı derecen farkı alındığında durağan olan seriler arasında eşbütünleşme testi yapılmasını, seriler arasında eşbütünleşme ilişkisinin çıkması durumunda, bu serilerin düzey değerleriyle yapılacak analizlerinde sahte regresyon sorununu barındırmayacağını belirtmiştir (Yiğidim ve Köse, 1997: 73). Bu şekilde başlayan geleneksel (yapısal kırılmaları göz önünde bulundurmayan) eşbütünleşme testleri, Johansen(1988), Pesaran, vd. (2001) vb. testleri ile devam etmiştir.

Birim kök testlerinde olduğu gibi eşbütünleşme testlerinde de analiz döneminde yapısal kırılmaların göz önünde bulundurulmaması, hatalı sonuçlara ulaşılmasına neden olabilecektir. Bu sorunun çözebilmesi için yapısal kırılmalı eşbütünleşme testleri geliştirilmiştir. Bu testlerin ilklerinden olan Gregory ve Hansen (1996) ve Westerlund ve Edgerton (2006) testleri eşbütünleşme vektöründeki tek yapısal kırılmayı göz önünde bulundurabilirken, Maki (2012) testi 5 taneye kadar yapısal kırılmayı göz önünde bulundurarak eşbütünleşme ilişkisinin varlığını sınayabilmekte ve eşbütünleşme tarihlerini de belirleyebilmektedir. Maki (2012) eşbütünleşme testinde aşağıdaki modeller kullanılmaktadır (Maki, 2012: 2013):

Model 0: Sabit Terimde Kırılmalı, Trendsiz Model

$y_{t}=\mu+\sum_{i=1}^{k} \mu_{i} D_{i t}+\beta x_{t}+e_{t}$

Model 1: Sabit Terimde ve Eğimde Kırılmalı, Trendsiz Model

$y_{t}=\mu+\sum_{i=1}^{k} \mu_{i} D_{i t}+\beta x_{t}+\sum_{i=1}^{k} \beta_{i} x_{t} D_{i t}+e_{t}$

Model 2: Sabit Terimde ve Eğimde Kırılmalı, Trendli Model

$y_{t}=\mu+\sum_{i=1}^{k} \mu_{i} D_{i t}+\gamma t+\beta x_{t}+\sum_{i=1}^{k} \beta_{i} x_{t} D_{i t}+e_{t}$

Model 3: Sabit Terimde, Eğimde ve Trendde Kırılmalı Model

$y_{t}=\mu+\sum_{i=1}^{k} \mu_{i} D_{i t}+\gamma t+\sum_{i=1}^{k} \gamma_{i} D_{i t}+\beta x_{t}+\sum_{i=1}^{k} \beta_{i} x_{t} D_{i t}+e_{t}$ 
Maki (2012) Yapısal Kırılmalı Eşbütünleşme Testi'nin hipotezleri;

$H_{0}$ : Yapısal kırılmalar varken, eşbütünleşme yoktur.

$H_{1}$ : Yapısal kırılmalar varken, eşbütünleşme vardır.

biçimindedir. Bu hipotezleri sınamak için gerekli kritik değerler, Maki (2012: 2013) çalışmasında verilmiştir. Analizde kullanılan tüm değişkenlerin eş bütünleşme analiz sonuçları Tablo 2'de yer almaktadır.

Tablo 2. Yapısal Kırılmalı Eşbütünleşme Analiz Sonuçları

\begin{tabular}{|c|c|c|c|c|}
\hline & Model 0 & Kırılma Tarihleri & Model 1 & Kırılma Tarihleri \\
\hline İHR 15 & -3.928 & 2005:q3- 2017:q1 & -3.107 & 2015:q4-2014:q4 \\
\hline İHR 16 & -4.151 & 2006:q1-2010:q3 & $-6.039 *$ & $2005: q 2-2011: q 2$ \\
\hline İHR 17 & -3.461 & 2014:q4-2011:q1 & -3.402 & 2014:q4-2011:q1 \\
\hline İHR 18 & -2.766 & 2016:q2-2011:q1 & -3.593 & 2016:q2-2008:q3 \\
\hline İHR 19 & -3.587 & 2014:q3-2005:q4 & -3.911 & 2016:q2-2009:q2 \\
\hline İHR 20 & -4.134 & 2005:q1-2009:q2 & $-5.946^{*}$ & 2015:q1-2014:q2 \\
\hline İHR 21 & -3.561 & 2014:q4-2005:q4 & $-5.394 * *$ & 2014:q4- 2007:q4 \\
\hline İHR 22 & -4.374 & 2004:q3-2009:q3 & -4.519 & 2014:q3-2006:q2 \\
\hline İHR 223 & $-6.301^{*}$ & 2014:q4-2010:q3 & $-6.298 *$ & 2014:q4-2013:q3 \\
\hline İHR 24 & -3.892 & 2005:q3-2017:q1 & -4.224 & $2015: q 2-2010: q 3$ \\
\hline İHR 25 & -4.393 & 2007:q4-2009:q2 & -3.992 & 2014:q4-2006:q1 \\
\hline İHR 26 & -4.098 & 2008:q1-2005:q1 & -4.578 & 2008:q1-2005:q1 \\
\hline İHR 27 & $-5.102 * *$ & 2014:q1-2007:q4 & $-5.213 * *$ & 2012:q4-2009:q1 \\
\hline İHR 28 & -4.272 & 2007:q4-2005:q3 & -4.691 & 2007:q4-2016:q2 \\
\hline İHR 29 & -4.472 & 2007:q4-2014:q1 & -4.330 & $2007: q 4-2016: q 2$ \\
\hline İHR 30 & $-6.025^{*}$ & 2007:q3-2014:q1 & $-7.327^{*}$ & $2015: q 2-2016: q 2$ \\
\hline İHR 31 & -4.511 & 2006:q1-2015:q3 & $-5.255^{* *}$ & 2006:q1-2015:q3 \\
\hline İHR 32 & -4.512 & 2012:q3-2005:q4 & -4.199 & $2006: q 2-2011: q 2$ \\
\hline İHR 33 & -3.908 & 2005:q2-2013:q4 & -4.342 & 2010:q3-2014:q1 \\
\hline İHR 34 & -4.532 & 2014:q4-2007:q1 & -4.829 & 2014:q4-2011:q1 \\
\hline İHR 36 & -4.196 & 2008:q2-2014:q4 & -4.273 & 2014:q4-2005:q3 \\
\hline İHR 3351 & $-5.067^{* *}$ & 2010:q3-2014:q4 & -4.321 & 2007:q4-2004:q2 \\
\hline İHR 352 & $-6.180^{*}$ & 2008:q4-2011:q3 & $-6.286^{*}$ & 2015:q3-2009:q3 \\
\hline İHR 353 & $-7.622 *$ & 2012:q1-2009:q2 & $-7.449 *$ & 2011:q4-2006:q3 \\
\hline İHR 3359 & -3.758 & 2007:q3-2014:q2 & -4.127 & 2010:q4-2014:q1 \\
\hline İHR 2423 & -3.256 & 2008:q3-2005:q4 & -4.878 & $2015: q 2-2004: q 4$ \\
\hline
\end{tabular}


Teknoloji Yoğun Malların Sektörel İhracatt: Türkiye Örneği

Tablo 2 Devamı: Yapısal Kırılmalı Eşbütünleşme Analiz Sonuçları

\begin{tabular}{|c|c|c|c|}
\hline Model 2 & Kırılma Tarihleri & Model 3 & Kırılma Tarihleri \\
\hline-4.315 & 2006:q1-2014:q2 & $-6.256^{*}$ & 2013:q1-2005:q2 \\
\hline$-6.107 *$ & 2008:q3-2011:q3 & $-6.167^{*}$ & 2005:q2-2009:q3 \\
\hline-4.289 & 2012:q4-2010:q1 & $-5.574 *$ & 2010:q2-2005:q3 \\
\hline$-5.155 * * *$ & 2009:q3-2016:q2 & $-6.555^{*}$ & 2009:q3-2014:q1 \\
\hline-4.012 & 2016:q2-2003:q4 & $-5.889 *$ & 2011:q1-2007:q4 \\
\hline-4.430 & 2008:q1-2010:q3 & -4.953 & 2010:q1-2014:q2 \\
\hline-4.301 & 2014:q2-2004:q4 & $-5.168 *$ & 2010:q3-2005:q3 \\
\hline-4.783 & 2009:q3-2005:q3 & $-6.207^{*}$ & 2009:q3-2005:q3 \\
\hline$-6.680 *$ & 2011:q1-2014:q4 & $-6.333^{*}$ & 2011:q4-2010:q2 \\
\hline$-6.257^{*}$ & 2014:q3-2009:q1 & -3.540 & 2014:q4-2010:q3 \\
\hline$-5.150 * * *$ & 2014:q2-2008:q4 & $-5.725^{*}$ & 2010:q4-2005:q2 \\
\hline$-6.575^{*}$ & 2011:q2-2008:q1 & $-6.884 *$ & 2008:q2-2014:q2 \\
\hline-5.037 & 2007:q4-2014:q1 & $-5.776^{*}$ & 2012:q2-2009:q1 \\
\hline$-5.694 * * *$ & 2008:q1-2011:q3 & $-6.571^{*}$ & 2014:q2-2008:q3 \\
\hline$-5.930 * * *$ & 2007:q4-2011:q1 & $-5.964 *$ & 2012:q4-2008:q3 \\
\hline$-9.542 *$ & 2012:q3-2008:q4 & $-10.742 *$ & 2012:q3-2015:q3 \\
\hline-4.396 & 2008:q1-2010:q3 & $-5.327 * * *$ & 2011:q3-2004:q1 \\
\hline-4.785 & 2009:q1-2015:q4 & -4.877 & 2011:q4-2015:q4 \\
\hline-4.394 & 2010:q3-2003:q4 & $-5.347 * * *$ & 2012:q4-2008:q3 \\
\hline$-5.171 *$ & 2014:q3-2006:q1 & $-5.340 * * *$ & 2013:q2-2007:q1 \\
\hline-4.142 & 2008:q2-2012:q3 & $-5.071 * * *$ & 2010:q3-2014:q4 \\
\hline$-6.876^{*}$ & 2010:q3-2016:q1 & -4.692 & 2010:q3-2016:q2 \\
\hline$-6.128 *$ & 2011:q3-2007:q2 & $-5.347 * * *$ & 2015:q2-2010:q2 \\
\hline$-7.030 *$ & 2006:q3-2017:q1 & $-8.828 * * *$ & 2012:q1-2007:q4 \\
\hline-5.051 & 2013:q1-2008:q2 & $-5.715^{* * *}$ & 2011:q2-2009:q3 \\
\hline-3.558 & 2008:q3-2012:q3 & $-5.131 * * *$ & 2016:q2-2011:q3 \\
\hline
\end{tabular}

Yapılan analiz sonucunda, farklı kırılmaların altında durağan oldukları gözlemlenmiştir. $\mathrm{Bu}$ nedenle yapısal kırılmaları dikkate alan yöntem ile modellerin tahminleri yapılmıştır.

\subsection{FMOLS Yöntemi ve Tahmin Sonuçlart}

Eşbütünleşik seriler arasındaki uzun dönemli ilişkileri tespit etmede Sıradan En Kü̈cük Kareler (Ordinary Least Squares: OLS) yöntemi zayıf kalmakta, sapmalı sonuçlar üretebilmektedir (Camacho-Guti'errez, 2010: 3). Bu tür seriler arasındaki eşbütünleşme vektörünün Tam Değiştirilmiş En Küçük 
Kareler (Fully Modified Ordinary Least Squares: FMOLS), Dinamik En Küçük Kareler (Dynamic Ordinary Least Squares: DOLS) veya Kanonik Eşbütünleşik Regresyon (Canonical Cointegrating Regression: CCR) yöntemlerinden biriyle tahmin edilmesi daha doğru olacaktır (Polat, 2017: 308). Phillips ve Hansen (1990) tarafından geliştirilen yarı parametrik FMOLS yöntemi, OLS tahmincisinde ortaya çıkan bağımsız değişkenlerle hata terimi arasındaki otokorelasyon ve içsellik (endogeneity) sorunlarına bağlı sapmaları ortadan kaldıran, değişen varyans ve otokorelasyon sorunlarına karşı dirençli (robust) bir tahmincidir (Nazlıoglu, 2010: 99). FMOLS tahmincileri; asimptotik olarak sapmasız, süper tutarlı ve asimptotik olarak normal dağılıma sahiptir. $\mathrm{Bu}$ yöntemde kullanılan iki değişkenli model sistemine Model 11 ve 12 de yer verilmiştir (Erarslan, 2017: 122).

$$
\begin{gathered}
y_{t}=\beta^{\prime} x_{t}+u_{t}=\theta^{\prime} z_{t}+u_{t} \\
\Delta x_{t}=v_{t}
\end{gathered}
$$

Model 11' de yer alan fonksiyonun, merkezi limit teoremine uyum sağladığı, içsellik probleminden kaynaklanan otokorelasyon sorununu düzelttiği kabul edilmektedir (Shakeel, vd. 2014).

FMOLS yönteminin tercih edilmesinin nedeni gözlem sayısının düşük olduğu durumlarda serbestlik derecesini düşürmemesidir (Seck, 2012; Orman, 2015). Bu nedenle çalışmanın analizinde FMOLS yöntemi tercih edilmiştir. Sektörel bazda teknoloji yoğun malların ihracatının analizleri Tablo 3' de verilmiştir.

\begin{tabular}{|c|c|c|c|c|}
\hline & \multicolumn{4}{|c|}{ Yüksek Teknoloji Yoğun Mallar } \\
\hline & Sabit terim & GDP & RDK & Kriz \\
\hline İHR353 & $-86.08151^{*}$ & $6.401185^{*}$ & $-0.012925^{*}$ & -0.070419 \\
\hline İHR2423 & $-115.9726^{*}$ & $8.031633^{*}$ & $0.009390^{* * *}$ & $-0.502571 *$ \\
\hline İHR30 & $-115.0163^{* *}$ & $7.818918^{*}$ & $0.017904 *$ & $-0.283745^{* *}$ \\
\hline İHR32 & $48.99115^{*}$ & $-1.74736^{* * *}$ & 0.001633 & 0.174201 \\
\hline İHR33 & $-172.3024^{*}$ & $11.39746^{*}$ & 0.009839 & $-0.553338 *$ \\
\hline \multicolumn{5}{|c|}{ Orta Yüksek Teknoloji Yoğun Mallar } \\
\hline & Sabit terim & GDP & RDK & Kriz \\
\hline İHR31 & $-120.6558^{*}$ & $8.320738 *$ & $0.025080 *$ & $-0.38024 * * *$ \\
\hline İHR34 & $-95.93696^{*}$ & $7.027506^{*}$ & $0.008512 *$ & 0.043838 \\
\hline İHR24 & $-109.4917 *$ & $7.739907 *$ & $0.014193 *$ & $-0.451355^{* *}$ \\
\hline IHR352 & $-220.1762 *$ & $14.12231 *$ & 0.010970 & $-1.672203 * *$ \\
\hline IHR359 & $-34.03288^{*}$ & $2.982277^{*}$ & $0.010216^{*}$ & -0.159980 \\
\hline İHR29 & -111.3508 & 7.873368 & 0.015609 & $-0.30376^{* * *}$ \\
\hline
\end{tabular}

Tablo 3. FMOLS Tahmin Sonuçları 
Teknoloji Yoğun Malların Sektörel İhracatı: Türkiye Örneği

Tablo 3 Devamı. FMOLS Tahmin Sonuçları

\begin{tabular}{|c|c|c|c|c|}
\hline & \multicolumn{4}{|c|}{ Orta Düşük Teknoloji Yoğun Mallar } \\
\hline & Sabit terim & GDP & RDK & Kriz \\
\hline İHR351 & -28.05283 & $2.737687 * * *$ & $0.016169 * *$ & $0.713217 * *$ \\
\hline IHR25 & $-121.2080^{*}$ & $8.411262 *$ & $0.017832 *$ & $-0.433602 * *$ \\
\hline İHR23 & $-89.94779 *$ & $6.384340^{*}$ & $0.037358 *$ & -0.023935 \\
\hline İHR26 & $-37.38601 *$ & $3.383974 *$ & $0.014165^{*}$ & -0.072610 \\
\hline İHR27 & $-108.4664 *$ & $7.691587 *$ & $0.020814^{*}$ & -0.078433 \\
\hline İHR28 & $-110.6366^{*}$ & $7.777507 *$ & $0.017933 *$ & -0.297803 \\
\hline \multicolumn{5}{|c|}{ Düşük Teknoloji Yoğun Mallar } \\
\hline & Sabit terim & GDP & RDK & Kriz \\
\hline İHR36 & $-142.7223^{*}$ & $9.772833 *$ & 0.006365 & $-0.39227 * * *$ \\
\hline İHR21 & $-149.6491 *$ & $10.06884^{*}$ & $0.013278 * *$ & $-0.55861 * *$ \\
\hline İHR22 & $-39.57909 *$ & $3.300583 *$ & $0.016581 *$ & -0.173526 \\
\hline İHR15 & $-110.309^{*}$ & $7.829 *$ & $0.011 * *$ & $-0.476^{* *}$ \\
\hline İHR16 & -193.0274 & 12.60890 & $0.010973 * * *$ & $-0.538855^{* *}$ \\
\hline İHR17 & $-47.15169 *$ & $4.099030 *$ & $0.005970 * *$ & $-0.18335 * * *$ \\
\hline İHR18 & $-16.06296 *$ & $2.243701 *$ & $0.003971 * *$ & -0.056425 \\
\hline İHR19 & $-118.5418 *$ & $8.196570^{*}$ & $0.009201 * * *$ & $-0.466359 * *$ \\
\hline İHR20 & -132.1113 & 8.921026 & 0.019531 & -0.398842 \\
\hline
\end{tabular}

*\%1; ** \%5 ve *** \%10 anlamlılık düzeylerini göstermektedir.

Hava ve uzay taşıtları sektörü (İHR353), tıpta ve eczacılıkta kullanılan kimyasal ve bitkisel kaynaklı ürünler sektörü (IHHR2423), büro, muhasebe ve bilgi işleme makinaları sektörü (IHR30), radyo, televizyon, haberleşme teçhizatı ve cihazları sektörü (İHR32) ve tıbbi aletler; hassas optik aletler ve saat sektörü (IHHR33) ihracatları yüksek teknolojili ürün ihracatı olarak kabul edilmektedir. Bu sektörlerin ihracatı dış geliri ifade eden AB'nin milli gelirinden anlamlı bir şekilde etkilenmektedir. Söz konusu bu etki radyo, televizyon, haberleşme teçhizatı ve cihazları sektörü ihracatı hariç pozitif yöndedir. Yani AB'nin milli gelirindeki artış sadece radyo, televizyon, haberleşme teçhizatı ve cihazları sektörünün ihracatını azaltmaktadır. Böyle bir sonucun ortaya çıkmasının nedeni, AB'nin gelir artışı bu sektöre ait ihtiyaçlarını başka ülkelerden karşıladığını göstermektedir. Reel döviz kuru ise radyo, televizyon, haberleşme teçhizatı ve cihazları ve tıbbi aletler; hassas optik aletler ve saat sektörlerinin 
ihracatı hariç, diğer sektörlerin ihracatlarını anlamlı bir şekilde etkilemektedir. Reel döviz kurundaki artış, yani yerli paranın değer kaybı tıpta ve eczacılıkta kullanılan kimyasal ve bitkisel kaynaklı ürünler ve büro, muhasebe ve bilgi işleme makinaları sektörlerine olan talebi artırmakta, hava ve uzay taşıtları sektörlerinin ihracatını ise azaltmaktadır. Yerli paranın değerindeki artış, ihracatın azalmasına neden olmaması beklentiler ile uyuşmamaktadır. Kriz değişkeni ise tıpta ve eczacılıkta kullanılan kimyasal ve bitkisel kaynaklı ürünler, büro, muhasebe ve bilgi işleme makinaları ve tıbbi aletler; hassas optik aletler ve saat sektörlerinin ihracatını olumsuz etkilerken, hava ve uzay taşıtları ve radyo, televizyon, haberleşme teçhizatı ve cihazları sektörlerinin ihracatı üzerinde etkisi yoktur.

Başka yerde sınıflandırılmamış elektrikli makine ve cihazlar sektörü (IHR31), motorlu kara taşı11 ve römorklar sektörü (İHR34), kimyasal madde ve ürünler (2423 hariç) sektörü (İHR34), demiryolu ve tramvay lokomotifleri ile vagonları sektörü (İHR352), başka yerde sınıflandırılmamış ulaşım araçları ve başka yerde sınıflandırılmamış makine ve teçhizat sektörü ihracatları orta yüksek teknolojili ürün ihracatı olarak kabul edilmektedir. AB'nin milli geliri, başka yerde sınıflandırılmamış elektrikli makine ve cihazlar, motorlu kara taşıtı ve römorklar, kimyasal madde ve ürünler (2423 hariç), demiryolu ve tramvay lokomotifleri ile vagonları sektörü (IHHR352), başka yerde sınıflandırılmamış ulaşım araçları (İHR359) ve başka yerde sınıflandırılmamış makine ve teçhizat sektörlerinin (IHR29) ihracatını pozitif ve anlamlı bir şekilde etkilemektedir. AB'nin gelirindeki artış söz konusu sektörlerin ihracatını artırmaktadır. Demiryolu ve tramvay lokomotifleri ile vagonları sektörü hariç diğer sektörlerin ihracatı ise reel döviz kurundaki artıştan pozitif yönde etkilenmektedir. Kriz değişkeni ise sadece başka yerde sınıflandırılmamış ulaşım araçları ve motorlu kara taşıtı ve römorklar sektörünün ihracatlarını etkilememekte, diğer sektörlerin ihracatını azaltmaktadır.

Deniz taşıtları sektörü (İHR351), plastik ve kauçuk ürünleri sektörü (IHHR25), kok kömürü, rafine edilmiş petrol ürünleri ve nükleer yakıtlar sektörü (IHHR23), metalik olmayan diğer mineral ürünler sektörü (İHR26), ana metal sanayi sektörü (IHR27) ve metal eşya sanayi (makine ve teçhizatı hariç) sektörü (IHHR28) ihracatları orta düşük teknoloji ihracatı olarak kabul edilmektedir. Deniz taşıtları, plastik ve kauçuk ürünleri, kok kömürü, rafine edilmiş petrol ürünleri ve nükleer yakıtlar, metalik olmayan diğer mineral ürünler, ana metal sanayi ve metal eşya sanayi (makine ve teçhizatı hariç) sektörü AB'nin milli gelirinden ve reel döviz kurundan pozitif ve anlamlı bir şekilde etkilemektedir. Kriz değişkeni ise sadece deniz taşıtları ve plastik ve kauçuk ürünleri sektörlerinin ihracatlarını negatif ve anlamlı bir şekilde etkilerken, diğer sektörlerin ihracatına etkisi ise anlamsızdır.

Mobilya ve başka yerde sınıflandırılmamış diğer ürünler sektörü (IHHR36), kağıt ve kağıt ürünleri sektörü (İHR21), basım ve yayım; plak, kaset vb. sektörü (İHR22) sektörü, gıda ürünleri ve içecek sektörü (İHR15), tütün 
ürünleri sektörü (İHR16), tekstil ürünleri sektörü (İHR17), giyim eşyas1 sektörü (IHHR18), dabaklanmış deri, bavul, el çantası, saraciye ve ayakkabı sektörü (IHHR19) ve ağaç ve mantar ürünleri (mobilya hariç); hasır vb. örülerek yapılan maddeler sektörü (IHR20) ihracatları düşük teknoloji ihracatı olarak kabul edilmektedir. Dış geliri ifade eden AB'nin milli geliri mobilya ve başka yerde sınıflandırılmamış diğer ürünler kağıt ve kağıt ürünleri, basım ve yayım; plak, kaset vb., gida ürünleri ve içecek, tütün ürünleri, tekstil ürünleri, giyim eşyası, dabaklanmış deri, bavul, el çantası, saraciye ve ayakkabı ve ağaç ve mantar ürünleri (mobilya hariç); hasır vb. örülerek yapılan maddeler sektörlerinin ihracatını pozitif ve anlamlı bir şekilde etkilemektedir. Reel döviz kuru değişkeni ise mobilya ve başka yerde sınıflandırılmamış diğer ürünler sektörü ihracatı hariç diğer sektörlerin ihracatını pozitif ve anlamlı bir şekilde etkilemektedir. Kriz değişkeni ise basım ve yayım; plak, kaset vb. ve giyim eşyası sektörlerinin ihracatı hariç, diğer sektörlerin ihracatını negatif ve anlamlı bir şekilde etkilemektedir.

\section{Sonuç}

Literatür taramasında yer verilen çalışmalarda, dış gelirin, döviz kurunun ve ekonomik krizlerin ülkelerin ihracat hacimleri üzerinde etkisi olabileceği ortaya çıkmıştır. Bu bağlamda, çalışma da Türkiye'nin teknoloji yoğun mal ihracatına dış gelirin, döviz kurunun ve ekonomik kriz (kukla) değişkeninin etkisi 26 sektör ihracatı için regresyon analizleriyle incelenmiştir. Yapılan ekonometrik analizlerden elde edilen sonuçlara göre yüksek ve orta-yüksek teknoloji ürünleri sektörleri ihracatının reel döviz kuru ve dış talep esnekliğinin, diğer sektörlerden daha yüksek olduğu tespit edilmiştir. Ayrıca, reel döviz kurunun ve GSYİH'nin ihracat üzerindeki etkisi her sektör için farklı sonuçlar vermektedir. Dolayısıyla analize dâhil edilen sektörler için genelleme yapılması mümkün olmamaktadır.

Türkiye'nin imalat sanayi ihracatının yarısından fazlasını düşük ve orta düşük teknolojili mallar oluşturmaktadır. Türkiye'nin düşük teknolojili mallarda ticaret fazlası verdiği ancak bu oranın dönem içinde azalma eğiliminde olduğu bilinmektedir. İmalat sanayinde yüksek ve orta-yüksek teknoloji ürünleri sektörleri ihracatının reel döviz kuru ve diş talep esnekliğinin, diğer sektörlerden daha yüksek olduğu tespit edilmiştir. Ayrıca, reel döviz kurunun dış ticarete etkisi sektörlerin teknoloji yoğunluğu, ürün yetkinliği, ithal girdi bağımlılığı ve ihracat yönelim derecelerine göre değişmektedir. Türkiye'nin teknoloji yoğun malların üreticisi ve ihracatçısı olması daha yüksek oranda ve istikrarlı bir şekilde ekonomik büyüme sağlaması için çok önemlidir. $\mathrm{Bu}$ nedenle Türkiye'de izlenen sanayi ve teşvik politikalarının, teknoloji yoğun malların üretimini öncelik verecek şekilde dizayn edilmesinde yarar vardır. 


\section{Kaynaklar}

Calvino, F., Criscuolo, C., Marcolin, L., and Squicciarini, M. (2018). A taxonomy of digital intensive sectors. OECD Science, Technology and Industry Working Papers, 2018.

Dikmen, N. (2012). Ekonometri Temel Kavram ve Uygulamalar. Bursa: Dora Yayınevi.

Ekizceleroğlu, C. (2008). Bilgi Ekonomisinin Dış Ticaret İçindeki Yeri: Türkiye Örneği. Trakya Üniversitesi, Sosyal Bilimler Enstitüsü, İktisat Anabilim Dalı, Yayımlanmamış Yüksek Lisans Tezi.

Ekizceleroğlu, C. (2011). Türkiye'de Bilgi Ekonomisi ve Bilgi Yoğun Malların Dış Ticareti (1969-2009). Marmara Üniversitesi İIBBF Dergisi, 30(1), 209228.

Erarslan, B. (2017). Altın Fiyatını Belirleyen Talep Yönlü Faktörlerin Analizi: Türkiye İçin Bir Uygulama. Sakarya Üniversitesi, Sosyal Bilimler Enstitüsü, İktisat Anabilim Dalı, Yayımlanmamış Yüksek Lisans Tezi.

Fotros, M. H. and Ahmadvand N. (2017). The Impact of Import and Export of Medium Technology Industries on Economic Growth of Iran. International journal of bussines and development studies, 9(2), 139-161.

Glynn, H., Perera, N. and Verma, V. (2007). Unit Root Tests and Structural Breaks: A Survey with Applications. University of Wollongong, Research. 44, 1-17.

Göçer, İ. (2013). Ar-Ge Harcamalarının Yüksek Teknolojili Ürün İhracatı, Dış Ticaret Dengesi ve Ekonomik Büyüme Üzerindeki Etkileri. Maliye Dergisi, 165(2), 215-240.

Granger, C. W. J, and Newbold, P. (1974). Spurious Regressions in Econometrics. Journal of Econometrics, 2 (2), 111-120.

Işık, N. ve Kılınç E. (2013). Bilgi ekonomisi ve iktisadi büyüme : OECD ülkeleri üzerine bir uygulama Akdeniz İ.İ.B.F. Dergisi (26), 21-54.

Kılıç C., Bayar Y. ve Özekicioğlu H. (2014). Araştırma geliştirme harcamalarının ileri teknoloji ürün ihracatı üzerindeki etkisi: G-8 ülkeleri için bir panel veri analizi. Erciyes üniversitesi İ̈BF Dergisi, 44, 115-130.

Kızılkaya O., Sofuoğlu E. ve Ay A. (2017). Yüksek teknolojili ürün ihracatı üzerinde doğrudan yabancı sermaye yatırımları ve dışa açıklığın etkisi: gelişmekte olan ülkelerde panel veri analizi. Doğuş Üniversitesi Dergisi 18(1), 63-78.

Lee, J. and Strazicich, M.C. (2003). Minimum Lagrange Multiplier Unit Root Test With Two Structural Breaks. The Review of Economics and Statistics, 85(4), 1083-1082.

Lee, J. and Strazicich, M.C. (2004). Minimum LM Unit Root Test with One Structural Break. Appalachian State University Working Papers, No:04$17,1-15$.

Lee J. and Strazicich M. C. (2013). Minimum LM Unit Root Test With One Structural Break. Economic Bulletin, 33(4), 2483-2492. 
Maki, D. (2012). Tests For Cointegration Allowing For an Unknown Number of Breaks. Economic Modelling, 29(5), 2011-2015.

Nazlığlu, Ş. (2010). Makro İktisat Politikalarının Tarım Sektörü Üzerindeki Etkileri: Gelişmiş ve Gelişmekte Olan Ülkeler İçin Bir Karşılaştırma. Erciyes Üniversitesi, Sosyal Bilimler Enstitüsü, İktisat Anabilim Dalı, Yayımlanmamış Doktora Tezi.

OECD. (2011). Industry and entrepreneur ship. Retrieved from https://www.oecd.org/.

OECD. (2007). Industry and entrepreneur ship. Retrieved from https://www.oecd.org/.

Özdamar, G. (2014). İmalat sanayisinde Türkiye'nin AB ile ticaretinin yapısı ve rekabet gücü: Teknoloji düzeylerine göre bir inceleme. Dumlupınar Üniversitesi Sosyal Bilimler Dergisi ,41, 11-30.

Özer, M., ve Çiftçi, N. (2009). Ar-Ge Harcamaları ve İhracat İlişkisi: OECD Ülkeleri Panel Veri Analizi. Dumlupınar Üniversitesi, Sosyal Bilimler Dergisi (23), 39-50.

Özkan G. ve Yılmaz H. (2017). Ar-Ge harcamalarının yüksek teknolojili ürün ihracatı ve kişi başı gelir üzerindeki etkileri $12 \mathrm{AB}$ ülkesi ve Türkiye için uygulama (1996-2015), Bilgi Ekonomisi ve Yönetimi Dergisi, 7(1), 1-12.

Sandu, S. and Ciocanel B. (2014). Impact of R\&D andInnovation on High-tech Export. Procedia Economics and Finance (15),80-90.

Saygil1, Ş. (2003). Bilgi Ekonomisine Geçiş Sürecinde Türkiye Ekonomisinin Dünyadaki Konumu. Ankara: Devlet Planlama Teşkilatı Yayın No. DPT: 2675.

Sekmen, F. (2013). İmalat Sanayi Dış Ticaret Analizi. Türkiye Kalkınma Bankası Yayını, 70, 2-10.

Seyoum, B. (2004). The role of factor conditions in high-technology exports: An empirical examination. The Journal of High Technology Management Research, 15(1), 145-162.

Şahbaz, A., Yanar, B. ve Adıgüzel, U. (2014). Ar-Ge harcamaları ve ileri teknoloji mal ihracatı ilişkisi: Panel nedensellik analizi. Ç.Ü. Sosyal Bilimler Enstitüsü Dergisi, 23(1), 47-60.

Şahin, D. (2016). Faktör Yoğunluğuna Göre Endüstri-İçi Ticaretin Statik Ölçümü: Türkiye Örneği. Akademik Bakış Uluslararası Hakemli Sosyal Bilimler Dergisi, 54, 174- 187.

Şahin, M. ve Aşan, S. (2015). Küresel Krizin OECD Ülkeleri Bilgi ve İletişim Teknolojileri (Bit) İhracatı Üzerine Etkisi. Journal of Life Economics, 1, 27-46.

Shakeel, M., Iqbal, M. and Majeed, M. T. (2014) Energy Consumption, Trade and GDP: A Case Study of South Asian Countries. The Pakistan Development Review, 53(4), 461-476.

Telatar M.O., Değer K. M. ve Doğanay A. M. (2016). Teknoloji Yoğunluklu Ürün İhracatının Ekonomik Büyümeye Etkisi: Türkiye Örneği (1996:q1- 
2015:q3), Atatürk Üniversitesi İktisadi ve İdari Bilimler Dergisi, 30, (4), 921-934.

Topallı, N. (2008). Doğrudan Yabancı Sermaye Yatırımları ve Ekonomik Büyüme: Türkiye Deneyimi 1992-2007. Gaziantep Üniversitesi Sosyal Bilimler Dergisi, 7(1), 79-89.

Yıldız, Ü. (2017). BRICS ülkeleri ve Türkiye' de ileri teknoloji ihracatı ve ekonomik büyüme ilişkisinin panel veri analizi. Dumlupınar Üniversitesi Sosyal Bilimler Dergisi, 53(2), 26-34.

Yiğidim, A. ve Köse, N. (1997). İhracat ve Ekonomik Büyüme Arasındaki İlişki, İthalatın Rolü: Türkiye Örneği (1980-1996). Ekonomik Yaklaşım, 8(26), 71-85.

Yücel Y. (2016). Bilgi ekonomisi ve diş ticaret ilişkileri: yükselen ekonomiler örneği. ETÜ Sosyal Bilimler Enstitüsü Dergisi 3(6), 33-55.

Zivot, E. and Andrews, D. W. K. (1992). Further Evidence on the Great Crash, the Oil Price Shock, and the Unit-Root Hypo thesis. Journal of Business and Economic Statistics, 10(3), 251-270.

Ek.1. Değişkenler

\begin{tabular}{lll}
\hline Değişken & \multicolumn{1}{c}{ Değişkenin Tanımı } & Kaynak \\
\hline IHR & $\begin{array}{l}\text { Türkiye'nin teknoloji yoğunluğuna göre imalat } \\
\text { sanayi ürün gruplarının sektörel ihracatıdır. Avro } \\
\text { cinsinden veriler olup, uçer aylık şeklinde analize } \\
\text { dahil edilmiş ve logaritmaları alınmıştır. }\end{array}$ & TÜIK \\
\hline RDK & Türkiye'nin reel döviz kur endeksidir. & TCMB \\
\hline GSYİH & $\begin{array}{l}\text { AB'ye ait Gayri Safi Yurtiçi Hasıla verisidir. Avro } \\
\text { cinsinden veriler olup, ücrer aylık şeklinde analize } \\
\text { dahil edilmiş ve logaritmaları alınmıştır. }\end{array}$ & Eurostat \\
\hline Kriz & $\begin{array}{l}\text { 2008-2010 küresel ekonomik krizin etkilerini ifade } \\
\text { eden kukla değişkenidir. }\end{array}$ & $\begin{array}{l}\text { Yazarlar tarafından } \\
\text { oluşturulmuşur }\end{array}$ \\
\hline
\end{tabular}


Teknoloji Yoğun Malların Sektörel İhracatı: Türkiye Örneği

Ek.2 . Teknoloji Yoğunluğuna Göre İmalat Sanayi Mal Grupları Sınıflaması

\begin{tabular}{|c|c|c|}
\hline Değişkenler & Kod & Yüksek Teknoloji Yoğun Mallar \\
\hline İHR353 & 353 & Hava ve uzay taşıtları \\
\hline İHR2423 & 2423 & $\begin{array}{l}\text { Tıpta ve eczacılıkta kullanılan kimyasal ve bitkisel kaynaklı } \\
\text { ürünler }\end{array}$ \\
\hline İHR30 & 30 & Büro, muhasebe ve bilgi işleme makinaları \\
\hline İHR32 & 32 & Radyo, televizyon, haberleşme teçhizatı ve cihazları \\
\hline \multirow[t]{2}{*}{ İHR33 } & 33 & Tibbi aletler; hassas optik aletler ve saat \\
\hline & & Orta Yüksek Teknoloji Yoğun Mallar \\
\hline İHR31 & 31 & Başka yerde sınıflandırılmamış elektrikli makine ve cihazlar \\
\hline IHR34 & 34 & Motorlu kara taşıtı ve römorklar \\
\hline IHR24 & 24 & Kimyasal madde ve ürünler (2423 hariç) \\
\hline IHR352 & 352 & Demiryolu ve tramvay lokomotifleri ile vagonları \\
\hline İHR359 & 359 & Başka yerde sınıflandırılmamış ulaşım araçları \\
\hline \multirow[t]{2}{*}{ İHR29 } & 29 & Başka yerde sınıflandırılmamış makine ve teçhizat \\
\hline & & Orta Düşük Teknoloji Yoğun Mallar \\
\hline İHR351 & 351 & Deniz taşıtları \\
\hline IHR25 & 25 & Plastik ve kauçuk ürünleri \\
\hline İHR23 & 23 & Kok kömürü, rafine edilmiş petrol ürünleri ve nükleer yakıtlar \\
\hline İHR26 & 26 & Metalik olmayan diğer mineral ürünler \\
\hline İHR27 & 27 & Ana metal sanayi \\
\hline \multirow[t]{2}{*}{ İHR28 } & 28 & Metal eşya sanayi (makine ve teçhizatı hariç) \\
\hline & & Düşük Teknoloji Yoğun Mallar \\
\hline İHR36 & 36 & Mobilya ve başka yerde sınıflandırılmamış diğer ürünler \\
\hline İHR37 & 37 & Yeniden Değerlendirme \\
\hline İHR21 & 21 & Kağıt ve kağıt ürünleri \\
\hline İHR22 & 22 & Basım ve yayım; plak, kaset vb. \\
\hline İHR15 & 15 & Gıda ürünleri ve içecek \\
\hline İHR16 & 16 & Tütün ürünleri \\
\hline IHR17 & 17 & Tekstil ürünleri \\
\hline İHR18 & 18 & Giyim eşyası \\
\hline IHR19 & 19 & Dabaklanmış deri, bavul, el çantası, saraciye ve ayakkabı \\
\hline İHR20 & 20 & $\begin{array}{l}\text { Ağaç ve mantar ürünleri (mobilya hariç); hasır vb. örülerek } \\
\text { yapılan maddeler }\end{array}$ \\
\hline \multicolumn{3}{|c|}{$\begin{array}{l}\text { Sınıflamalar; Türkiye'nin dış ticaret istatistiklerini derlemede Birleşmiş Milletler'in } \\
\text { Harmonize Sistemi (HS) esas alınmaktadır. Ayrıca, SITC Rev.4, SITC Rev.3, SITC } \\
\text { Rev.2, ISIC Rev.4, ISIC Rev.3, ISIC Rev.2, BEC, CPA, CPC, NST2007 ve Teknoloji } \\
\text { Yoğunluğuna Göre Ürün Grupları sınıflamasına göre veri bulunmaktadır. Ayrıntılı bilgi } \\
\text { için bakınız. http://www.tuik.gov.tr/PreTablo.do?alt_id=1046 }\end{array}$} \\
\hline
\end{tabular}

